\title{
Total laparoscopic hysterectomy: a retrospective study of 5 years
}

\author{
Suma S. Moni, Suchith Hoblidar*, Rathnamala M. Desai, Sunil Kumar K. S.
}

Department of Obstetrics and Gynecology, Sri Dharmasthala Manjunatheshwara College of Medical Sciences and Hospital, Dharwad, Karnataka, India

Received: 17 September 2019

Accepted: 25 October 2019

\section{*Correspondence:}

Dr. Suchith Hoblidar,

E-mail: suchith.hoblidar@gmail.com

Copyright: () the author(s), publisher and licensee Medip Academy. This is an open-access article distributed under the terms of the Creative Commons Attribution Non-Commercial License, which permits unrestricted non-commercial use, distribution, and reproduction in any medium, provided the original work is properly cited.

\begin{abstract}
Background: Hysterectomy is one of the most common gynecological surgeries performed around the world. This study was done to review the data of all patients who underwent TLH. With this study a uniform method of performing TLH by a single surgeon was assessed.

Methods: A 5 years retrospective study was performed at Sri Dharmasthala Manjunatheshwara College of Medical Sciences and Hospital Dharwad, Karnataka India. Demographic data, pre-operative findings, indication for surgery, intra-operative and post-operative complications, duration of surgery were recorded and analyzed.

Results: A total of 118 women were included in the study. Mean age of the patients was

Most common indication for the surgery was leiomyoma. Mean operating time was 162.18 minutes. Mean weight of the post-operative specimen was 208.45 grams. Intra-operative urinary bladder injury was seen in 1 patient. Conversion to laparotomy was needed in 2 patients.

Conclusions: With improving experience TLH can be performed safely without complications. As number of surgeries done increases duration of TLH reduces. TLH can be effectively used to avoid laparotomy.
\end{abstract}

Keywords: Abnormal uterine bleeding, Hysterectomy, Learning curve, Operating time, Total laparoscopic hysterectomy

\section{INTRODUCTION}

Hysterectomy is one of the most common gynecological surgeries performed around the World. ${ }^{1}$ Although the exact prevalence of hysterectomy in India is not known, it is estimated to be 17 per 1000 married women. ${ }^{2}$ In spite of it being performed so commonly there has been a quest for an ideal method which would be safest, be of comfort and be cosmetically acceptable to the patients and cost effective. Majority of the hysterectomies are performed via the abdominal route. ${ }^{3}$ Abdominal route is favored route as it is easier to perform, doesn't require any specialized equipment or instruments, shorter learning curve. But there are disadvantages also and more so for the patients, chiefly being the post-operative pain, for which the main reason is the abdominal wall incision. ${ }^{4}$ Other drawbacks of abdominal hysterectomies are longer hospital stay, scar on the abdominal wall with less cosmetic appeal and future risk of hernias. Hysterectomy being performed laparoscopically and vaginally is slowly gaining popularity as they overcome the disadvantages of abdominal hysterectomy.

Laparoscopic hysterectomy was first reported by Reich in 1989. ${ }^{5}$ Although both vaginal and laparoscopic method are associated with great advantages, laparoscopy is preferred where a vaginal hysterectomy cannot be performed. In these patients' laparotomy and its associated risks can easily be avoided. Laparoscopic hysterectomy has certain advantages that is of great 
benefit to patients. It is associated with shorter hospital stay, faster post-operative recovery with less pain, lesser infections and absence of cosmetically unacceptable scar. ${ }^{6}$ Laparoscopy also comes with the added benefit of magnification and better visualization of pelvic structures. $^{7}$ Despite the advantages of laparoscopy, it is yet to gain popularity as a primary route for hysterectomy. This is because it has a long learning curve, surgeon needs patience to gain competence. Also, there is minimal training in laparoscopy during residency. It is more dependent on technology and requires costlier equipment's and instruments. It has been found that damage to urinary tract is more with laparoscopy and sometimes it is due to lateral spread of energy and the resultant ischemia. This fear of delayed injury is preventing most surgeons to shift to laparoscopic hysterectomy.

This study is aimed at knowing the feasibility of performing laparoscopic hysterectomies. Here we try to know the indications for surgery, the time taken to perform the surgery, complications involved and their management.

\section{METHODS}

A retrospective study was conducted at Sri Dharmasthala Manjunatheshwara College of Medical Sciences and Hospital Dharwad, Karnataka India from January 2014 to January 2019. Case records of all the patients who underwent total laparoscopic hysterectomy were reviewed. All the patients operated by the same surgeon were included in the study. Data regarding demographic details of patients, indication for hysterectomy, duration of surgery, energy source used, any intra-operative or post-operative complications were analyzed by calculations of percentages.

\section{Surgical method}

Uniform surgical technique was used to perform the surgery. Energy source used was either bipolar diathermy or the ultrasound energy. Pneumoperitoneum was created with veress needle. $10 \mathrm{~mm}$ primary port was created in the supra umbilical region. 2 lateral ports were created on the left side so that they made an isosceles triangle with primary port. One lateral port was created on the right side. Myoma screw was used to elevate the uterus. Round ligament, fallopian tube and ovarian ligament were coagulated and cut. Uterovesical fold of peritoneum was opened and bladder was pushed down. Posterior leaf of broad ligament was opened till the level of uterosacral ligament. Uterine artery was coagulated and cut. Makenrodt's ligament was coagulated and cut. Same procedure was repeated on the opposite side. Vaginal tube was used to elevate the vaginal vault and then was opened with monopolar energy source. All patients underwent bilateral salphingectomy. Ovaries were removed only in indicated patients. Vault was sutured with vicryl number 1 . All specimen was extracted by vaginal mechanical morcellation.

\section{RESULTS}

In this study there were a total of 118 patients who underwent laparoscopic hysterectomy over a period of 5 years. Majority of the patients, 46 (38.98\%) were belonging to the age group of 45-49 years (Figure 1). Mean age of the patients was 45.08 years. Most patients were parous except 3 patients being nulliparous.

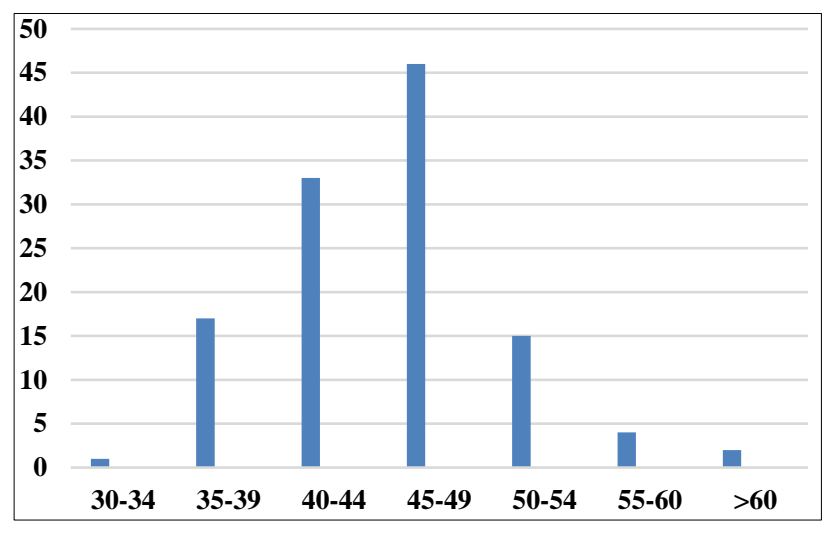

Figure 1: Mean age of the patients in years.

Table 1: Indications for TLH.

\begin{tabular}{|ll|}
\hline Indication & Number \\
\hline Leiomyoma & $62(52.54 \%)$ \\
\hline Endometrial hyperplasia & $17(14.40 \%)$ \\
\hline Adenomyosis & $15(12.71 \%)$ \\
\hline $\begin{array}{l}\text { AUB not relieved by medical } \\
\text { management }\end{array}$ & $9(7.62 \%)$ \\
\hline Leiomyoma and adenomyosis & $7(5.93 \%)$ \\
\hline Ovarian cyst & $5(4.23 \%)$ \\
\hline HSIL & $1(0.84 \%)$ \\
\hline LSIL & $2(1.69 \%)$ \\
\hline AUB: Abro
\end{tabular}

AUB: Abnormal uterine bleeding, HSIL: High grade squamous intra-epithelial neoplasia, LSIL: Low grade squamous intra-epithelial neoplasia.

Most common presenting symptom was heavy menstrual bleeding in $88(74.5 \%)$, followed by $13(11.01 \%)$ patients presenting with postmenopausal bleeding. Most common indication for the surgery was leiomyoma uteri in $62(52.54 \%)$ patients. Some patients had more than one indication for the surgery (Table 1).

On bimanual examination size of the uterus corresponded to 12 weeks gravid uterus in $32(27.11 \%)$ patients (Figure 2). Ovarian cyst was found on clinical examination among $5(4.23 \%)$ patients, largest one corresponding to 20 weeks.

There were $18(15.25 \%)$ patients with pre-existing hypertension, $6(5.08 \%)$ with type II diabetes, $5(4.23 \%)$ with both hypertension and type II diabetes, 6 (5.08\%) 
with hypothyroidism and $1(0.84 \%)$ with $\mathrm{HbsAg}$ positivity. There were $13(11.01 \%)$ patients with corrected anemia one among whom required blood transfusion (Table 2).

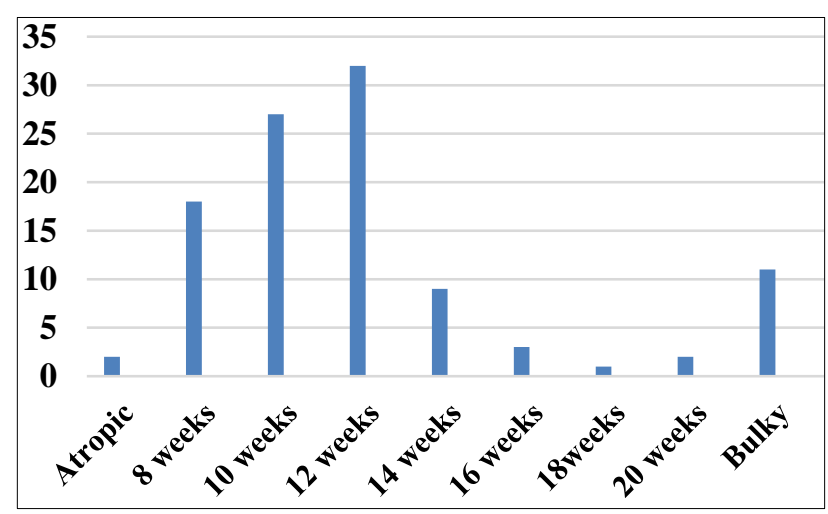

Figure 2: Size of uterus on clinical examination.

Table 2: Patients with medical illness.

\begin{tabular}{|ll|}
\hline Medical Illness & Number \\
\hline Type II diabetes mellitus & $6(5.08 \%)$ \\
\hline Hypertension & $18(15.25 \%)$ \\
\hline $\begin{array}{l}\text { Type II diabetes mellitus and } \\
\text { hypertension }\end{array}$ & $5(4.23 \%)$ \\
\hline Hypothyroidism & $6(5.08 \%)$ \\
\hline Anemia & $13(11.01 \%)$ \\
\hline Hepatitis B & $1(0.84 \%)$ \\
\hline
\end{tabular}

Table 3: Patients with prior surgeries.

\begin{tabular}{|ll|}
\hline Prior surgeries & Patients \\
\hline Abdominal tubal ligation & $38(32.20 \%)$ \\
\hline Laparoscopic sterilization & $7(5.93 \%)$ \\
\hline Previous cesarean & $8(6.77 \%)$ \\
\hline One cesarean & 5 \\
\hline Two cesareans & 2 \\
\hline Three cesareans & 1 \\
\hline Open myomectomy & $1(0.84 \%)$ \\
\hline Open cholecystectomy & $1(0.84 \%)$ \\
\hline Laparoscopic ovarian cystectomy & $1(0.84 \%)$ \\
\hline Hernia repair & $1(0.84 \%)$ \\
\hline Radical mastectomy & $1(0.84 \%)$ \\
\hline
\end{tabular}

Past history of undergoing surgery was present in 49 $(41.52 \%)$ patients. There were $38(32.20 \%)$ patients who had undergone abdominal tubectomy, 7 (5.93\%) laparoscopic sterilization, $1(0.84 \%)$ myomectomy, 1 $(0.84 \%)$ laparoscopic ovarian cystectomy and $1(0.84 \%)$ had undergone mastectomy. There were $8(6.77 \%)$ patients with history of previous cesarean of whom 5 had one previous surgery, 2 had 2 previous cesareans and 1 had 3 previous cesareans (Table 3 ).

Surgery done was hysterectomy with bilateral salphingectomy in $86(72.88 \%)$, hysterectomy with bilateral salphingo-oophorectomy in $25(21.18 \%)$, only hysterectomy in 3 (2.54\%). Energy source used harmonic ultrasonic device in $34(28.81 \%)$ patients and bipolar with monopolar electrocautery in $84(71.18 \%)$ patients. Vagina 1 vault was sutured vaginally in 46 (38.98\%) patients and laparoscopically in $72(61.01 \%)$. Time taken was $121-180$ minutes in most $65(55.08 \%)$. It was done in 120 minutes or less in $41(34.74 \%)$ patients. Time taken was more than 180 minutes in $12(10.16 \%)$ patients and in these patients, there was either history of previous cesareans or conversion to laparotomy or injury to other organs (Figure 3). Vaginal morcellation in patients with larger uteri prolonged the overall duration. Mean time for the surgery was 162.18 minutes. Blood loss was 100-150 $\mathrm{ml}$ in $56(47.45 \%)$ and less than $100 \mathrm{ml}$ in $51(43.22 \%)$ patients. Mean operating time has reduced over the 5 years (Figure 4).

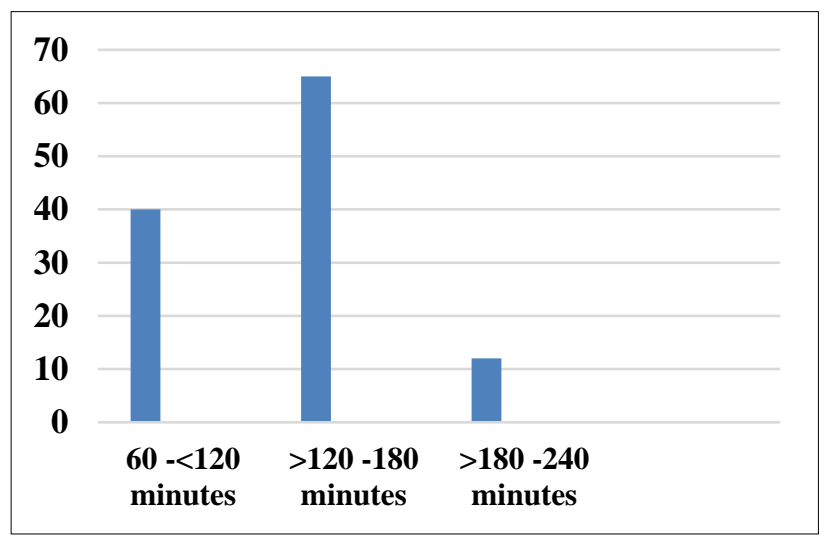

Figure 3: Mean time taken for TLH.

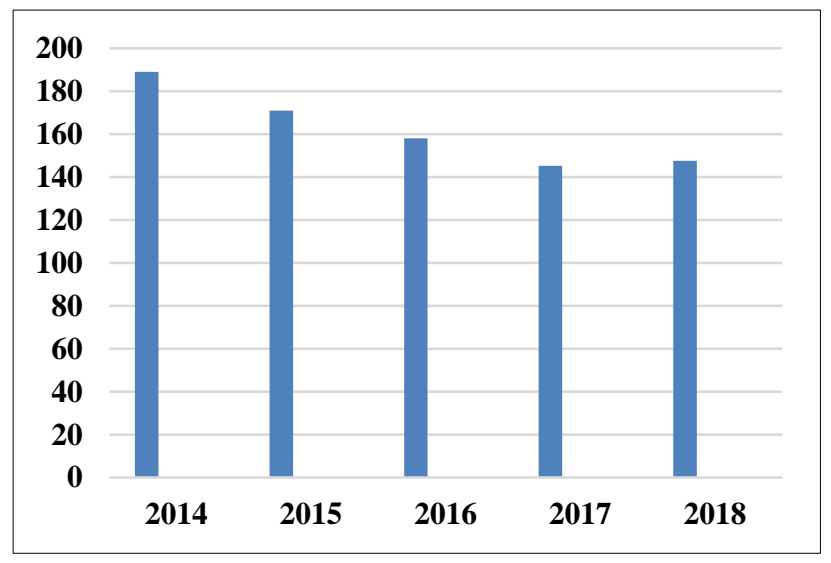

Figure 4: Mean time taken in minutes over 5 years.

The procedure was converted to laparotomy in $2(1.69 \%)$ and to laparoscopic assisted vaginal hysterectomy in 2 (1.69\%) patients. Reason for conversion to laparotomy was due to bladder injury in one patient and the other patient bladder was densely adherent due to previous 2 cesareans. There were 2 cases where the procedure was converted to vaginal as there was intractable bleeding near the uterosacral in one and in the other patient vault couldn't be opened because of cervical fibroid. Mini- 
laparotomy was done to retrieve the specimen in 2 patients. The size of the uterus was 20 weeks and 24 weeks and weighed 900 grams and 930 grams respectively.

\section{Table 4: Intra and post-operative complications.}

\begin{tabular}{|ll|}
\hline Complication & Number \\
\hline Injury to urinary bladder & $1(0.84 \%)$ \\
\hline Injury to bowel & $1(0.84 \%)$ \\
\hline Hemorrhage requiring blood transfusion & $1(0.84 \%)$ \\
\hline Secondary hemorrhage & $2(1.69 \%)$ \\
\hline
\end{tabular}

There was $1(0.84 \%)$ urinary bladder injury, was converted to laparotomy defect in the urinary bladder was repaired and the patient recovered uneventfully. There was $1(0.84 \%)$ case of superficial bowel injury which required suturing and patient recovered uneventfully. This bowel injury was due to direct application of heated but inactivated ultrasonic device. None of the patients had any complications in the immediate post-operative period except $1(0.84 \%)$ requiring blood transfusion postoperatively. All patients except $1(0.84 \%)$ with urinary bladder injury were discharged on fourth post-operative day. Mean hospital stay was 4.4 days. Delayed postoperative complications in the form of secondary haemorrhage was seen in $2(1.69 \%)$ patients. Both were treated conservatively with antibiotics and antifibrinolytics. Both the patients did not require readmission. There was no case intra-operative or delayed post-operative injury to the ureters in this study (Table 4).

Most of the patients were on regular follow up and none had any delayed post-operative complication except 14 $(11.86 \%)$ in whom there were symptoms of hot flashes. Among these 14 only 2 of the patients had undergone oophorectomy.

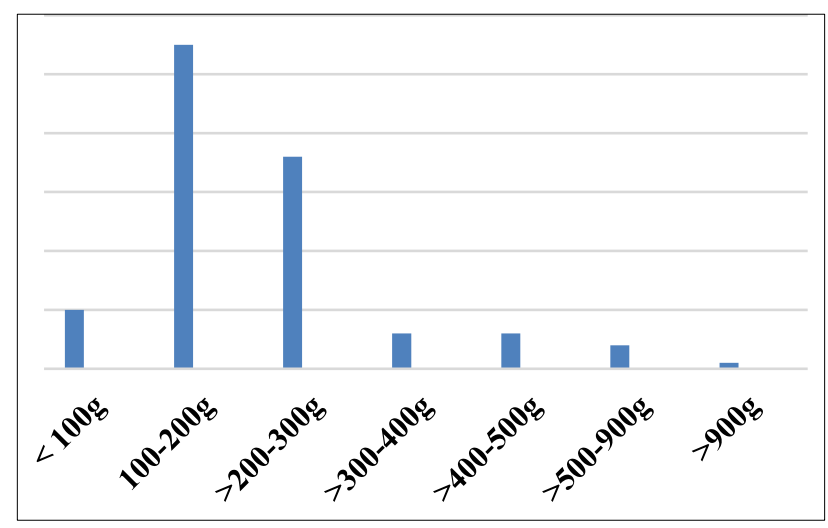

Figure 5: Weight of post-operative specimen in grams.

Examination of the operative specimen revealed that most of them, 55 (46.61\%) weighed between 100-200 grams. There were $36(30.50 \%)$ specimen whose weight was more than 200-300 grams. The largest specimen in this series weighed 900 grams and 930 grams. There were $10(8.47 \%)$ specimen with weight less than 100 grams.
Mean weight of the specimen was 208.45 grams (Figure $5)$. Microscopy of the specimen revealed leiomyoma in most, $44(37.28 \%)$ followed by $31(26.27 \%)$ patients with adenomyosis and leiomyoma. Endometrial hyperplasia was found in $21(17.79 \%)$ of whom 3 had atypia.

\section{DISCUSSION}

Patient satisfaction and wellbeing following any surgery is dependent on post-operative morbidity and hospital stay. The route which is associated with less of both, hospital stay and morbidity would be more acceptable to the patients. With increasing experience in laparoscopy and improvement in instrumentation TLH can be safely performed.

The findings in this study regarding mean age of the patients was 45.08 years and leading indications for hysterectomy being leiomyoma was similar to study done by Bonilla et al. ${ }^{8}$ With better pharmacological and nonsurgical methods available to treat most other causes of AUB, most studies report leiomyoma as the most common indication for hysterectomy as with the present study. ${ }^{9}$

Major complication rate was $2.54 \%$ slightly lower when compared with Bonilla et al where it was $3.9 \% .^{8}$ This was much higher compared to the study by Bettaiah et al where it was $0.9 \% .^{9}$ A complication rate of $4.5 \%$ was reported by O'Hanlan et al. ${ }^{10}$ Hoffman et al, had a major complication rate of $5.6 \%$, while Heinberg et al, had a major complication rate of $14.4 \%$, and Chapron reported complications in $10 \% .^{11-13}$

Urological complication in the present study was 1 $(0.84 \%)$ case of bladder injury. This was a patient in whom there was no previous surgery and the complication can be attributed to the inexperience of the surgeon as it was one of the first case to be operated. Bipolar electrocautery is known to be associated with greater lateral spread and the resultant ischemic injury to the ureter which is great deterrent to TLH. In majority of the cases in this series bipolar and monopolar energy source were used and despite this there has been no ureteric injury. Urological injuries during TLH were reported to be in the range of $0.05 \%-0.66 \%$ for bladder injuries and $0.02-0.4 \%$ for ureteric injuries. ${ }^{14}$

Various studies have compared $\mathrm{AH}, \mathrm{VH}$ and TLH in an attempt to conclude the best route for hysterectomy. TLH, when compared with $\mathrm{VH}$ a meta-analysis found no significant differences in urinary tract injuries between both methods. ${ }^{15}$ The eVALuate study is one such randomized study which concluded that LH is associated with less postoperative pain, quicker recovery, and better short-term quality of life. But the study also stated that LH was associated with longer operating time and urinary tract injuries when compared with $\mathrm{AH} .{ }^{16}$ However the conclusions from study has been widely questioned and high complication rates have been attributed to 
inexperience of the surgeon, non-standardized surgical procedure and faulty instruments. ${ }^{17-19} \mathrm{~A}$ meta-analysis comparing vaginal hysterectomy to laparoscopic hysterectomy showed no difference in complications and duration of hospital stay but vaginal hysterectomy was associated with shorter operative time, less vaginal cuff dehiscence and conversion to laparotomy whereas laparoscopic hysterectomy was associated with lower post-operative pain. ${ }^{20}$ When compared with abdominal hysterectomy many studies have reported that TLH has higher complication rates more pertaining to the injuries of the urinary tract. ${ }^{16,21}$ But there are studies now which state that in experienced hands and with a perfect technique TLH is not associated with any increase in major complications and even ureteric injuries are not more..$^{22,23}$

Effect of AH and TLH on post-operative vaginal length was compared which showed that it was shorter following $\mathrm{AH}$ and patients who have undergone TLH have better outcome related to certain sexual function parameters. ${ }^{24,25}$

Conversion rate in present study was $1.69 \%$ for laparotomy and $1.69 \%$ for vaginal hysterectomy. Conversion rate reported by Bettaiah $\mathrm{R}$ et al was $0.93 \%$ and Vaisbuch $\mathrm{E}$ et al was $1.8 \% .^{9,26}$ Conversion rate of $10.9 \%$ was reported by Sinha $\mathrm{R}$ et al where conversion was required for intractable hemorrhage, bladder injury and inability to reach all pedicles. ${ }^{27}$ There is similarity between this study and the present study regarding the reasons for conversion. Conversion rate also depends on the surgical volume at any institution which indicates that with improving skill of the operator conversion rate reduces. $^{28}$

Mean operating time in the study was 162.18 minutes. Bonilla et al reported mean operating time of 156 minutes. ${ }^{8}$ Begum $\mathrm{M}$ et al reported mean operating time of $148 \pm 40$ minutes. ${ }^{29}$ Mean operating time of $115 \pm 36$ minutes was noted by Mereu et al. ${ }^{30}$ This difference in mean operating time among different studies is because of the fact that TLH has a learning curve and a plateau as noted by various studies. Also, it was noted that the mean operating time has progressively reduced over the 5 years. Longer operating time in the present study can also attributed to the changing operating team with only the operating surgeon being constant. Also, it is noted that mean operating time has remained static in the last 2 years and this may be attributed to the fact that difficult surgeries were done in the recent years.

Various investigators have studied the learning curve for TLH. A study shows that the learning curve for TLH plateaus after about 75 cases after which operating time as well complication rates reduce. ${ }^{31,32}$

Cochrane review states that TLH can be done when VH is not possible to avoid $\mathrm{AH}^{33}$ The aim is to avoid laparotomy as far as possible so that complications due to laparotomy can be prevented.

\section{CONCLUSION}

TLH is an ideal approach to hysterectomy, especially in patients in whom vaginal hysterectomy cannot be done. With improving experience in TLH there is ample evidence stating that TLH could be done safely with no undue increase in complication rates. Of course, TLH is associated with longer operating time which also reduces as the surgeon's experience increases. Following a uniform surgical procedure and timing each step is the key to prevent complications and reduce the operating time.

\section{Funding: No funding sources \\ Conflict of interest: None declared \\ Ethical approval: Not required}

\section{REFERENCES}

1. Farquhar CM, Steiner CA. Hysterectomy rates in the United States 1990-1997. Obstet Gynecol. 2002;99:229-34.

2. Prusty RK, Choithani C, Gupta SD. Predictors of Hysterectomy among married women 15-49 years in India. Reprod Health. 2018;15:3.

3. Harry R, Lisa R. Laparoscopic hysterectomy in current gynecological practice. Gynocol Perinatal Prac. 2003;3:32-40.

4. Mathew P, Aggarwal N, Kumari K, Gupta A, Panda N, Bagga R. Quality of recovery and analgesia after total abdominal hysterectomy under general anesthesia: a randomized controlled trial of TAP block versus epidural analgesia versus parenteral medications. J Anaesthesiol Clin Pharmacol. 2019;35(2):170-5.

5. Reich H, DeCaprio J, McGlynn F. Laparoscopic hysterectomy. J Gynecol Surg. 1989;5:2:3-16.

6. Kim SM, Park EK, Jeung IC, Kim CJ, Lee YS. Abdominal, multi-port and single-port total laparoscopic hysterectomy: eleven-year trends comparison of surgical outcomes complications of 936 cases. Arch Gynecol Obstet. 2015;291:1313-9.

7. Donnez O, Jadoul P, Squifflet J, Donnez J. A series of 3190 laparoscopic hysterectomies for benign disease from 1990 to 2006: evaluation of complications compared with vaginal and abdominal procedures. BJOG. 2009;116:492-500.

8. Bonilla DJ, Mains L, Rice J, Crawford B. Total laparoscop- IC hysterectomy: our 5-year experience (1998-2002). The Ochsner J. 2010;10:8-12.

9. Bettaiah R, Reddy CA. Laparoscopic hysterectomies: our 10 years-experience in a single laparoscopic center. J Obstet Gynaecol India. 2016;66:274-81.

10. O'Hanlan KA, Dibble SL, Garnier AC, Reuland ML. Total laparoscopic hysterectomy: technique and complications of 830 cases. JSLS. 2007;11(1):45-53. 
11. Hoffman CP, Kennedy J, Borschel L, Burchette R, Kidd A. Laparoscopic hysterectomy: the Kaiser Permanente San Diego experience. J Minim Invasive Gynecol. 2005;12(1):16-24.

12. Heinberg EM, Crawford BL, Weitzen SH, Bonilla DJ. Total laparoscopic hysterectomy in obese versus nonobese patients. Obstet Gynecol. 2004;103(4):674-80.

13. Chapron C, Dubuisson JB, Ansquer Y, Fernandez B. Total hysterectomy for benign pathologies. Laparoscopic surgery does not seem to increase the risk of complications. J Gynecol Obstet Biol Reprod (Paris). 1998;27(1):55-61.

14. Adelman MR, Bardsley TR, Sharp HT. Urinary tract injuries in laparoscopic hysterectomy: a systematic review. J Minim Invasive Gynecol. 2014;21(4):55866.

15. Lee SH, Oh SR, Cho YJ, Han M, Park JW, Kim SJ, et al. Comparison of vaginal hysterectomy and laparoscopic hysterectomy: a systematic review and meta-analysis. BMC Women's Health. 2019;19(1):83.

16. Garry R. The eVALuate study: two parallel randomised trials, one comparing laparoscopic with abdominal hysterectomy, the other comparing laparoscopic with vaginal hysterectomy. BMJ. 2004;328:129.

17. Canis MJ, Wattiez A, Mage G, Bruhat MA. Results of eVALuate study of hysterectomy techniques: laparoscopic hysterectomy may yet have a bright future. BMJ. 2004;328:642-3.

18. Donnez J, Squifflet J, Jadoul P, Smets M. Results of eVALuate study of hysterectomy techniques: high rate of complications needs explanation. BMJ. 2004;328:643.

19. Garry R. Re-evaluating the eVALuate study and the NICE guidelines: a personal review. An Int J Obstet Gynaecol. 2016;123(11):1796.

20. Sandberg EM, Twijnstra ARH, Driessen SRC, Jansen FW. Total laparoscopic hysterectomy versus vaginal hysterectomy: a systematic review and metaanalysis. J Minim Invasive Gynecol. 2017;24(2):20617.

21. Johnson N, Barlow D, Lethaby A, Tavender E, Curr L, Garry R. Methods of hysterectomy: systematic review and meta-analysis of randomised controlled trials. BMJ. 2005;330(7506):1478.

22. McMaster-Fay RA, Jones RA. Laparoscopic hysterectomy and ureteric injury: a comparison of the initial 275 cases and the last 1,000 cases using staples. Gynecol Survey. 2006;3(2):118-21.

23. Donnez O, Jadoul P, Squifflet J, Donnez J. A series of 3190 laparoscopic hysterectomies for benign disease from 1990 to 2006: evaluation of complications compared with vaginal and abdominal procedures. BJOG. 2009;116(4):492-500.

24. Polat M, Kahramanoglu I, Senol T, Senturk B, Ozkaya E, Karateke A. J comparison of the effect of laparoscopic and abdominal hysterectomy on lower urinary tract function, vaginal length, and dyspareunia: a randomized clinical trial. J Laparoendosc Adv Surg Tech. 2016;26(2):116-21.

25. Kürek Eken $M$, İlhan $G$, Temizkan O, Çelik EE, Herkiloğlu D, Karateke A. The impact of abdominal and laparoscopic hysterectomies on women's sexuality and psychological condition. Turk J Obstet Gynecol. 2016;13(4):196-202.

26. Vaisbuch E, Goldchmit C, Ofer D, Agmon A, Hagay Z. Laparoscopic hysterectomy versus total abdominal hysterectomy: a comparative study. Eur J Obstet Gynecol Reprod Biol. 2006;126(2):234-8.

27. Sinha R, Swarnasree G, Rupa B, Madhumathi S. Laparoscopic hysterectomy for large uteri: Outcomes and techniques. J Minim Access Surg. 2019;15(1):813.

28. Keurentjes JHM, Briët JM, de Bock GH, Mourits MJE. Surgical volume and conversion rate in laparoscopic hysterectomy: does volume matter? A multicenter retrospective cohort study. Surg Endosc. 2018;32(2):1021-6.

29. Begum M, Zulfiqar N, Yasmin F. Total laparoscopic hysterectomy: a two-year experience in Apollo Hospitals Dhaka. Pulse. 2015;8(1):21-9.

30. Mereu L, Carlin R, Pellegrini A, Guasina F, Berlanda $\mathrm{V}$, Tateo S. Total laparoscopic hysterectomy for benign disease: outcomes and literature analysis. Gynecol Surg. 2018;15(1):19.

31. Terzi H, Biler A, Demirtas O, Guler OT, Peker N, Kale A. Total laparoscopic hysterectomy: Analysis of the surgical learning curve in benign conditions. Int J Surg. 2016;35:51-7.

32. Wattiez A, Soriano D, Cohen SB, Nervo P, Canis M, Botchorishvili R, et al. The learning curve of total laparoscopic hysterectomy: comparative analysis of 1647 cases. J Am Assoc Gynecol Laparosc. 2002;9(3):339-45.

33. Aarts JWM, Nieboer TE, Johnson N, Tavender E, Garry R, Mol BJ, et al. Surgical approach to hysterectomy for benign gynaecological disease. Cochrane Database Syst Rev. 2015;8:CD003677.

Cite this article as: Moni SS, Hoblidar S, Desai RM, Kumar KSS. Total laparoscopic hysterectomy: a retrospective study of 5 years. Int J Reprod Contracept Obstet Gynecol 2019;8:5008-13. 